\author{
Cadernos de \\ ESTUDOS LINGǘĺsTICOS - (57.2), Campinas, Jul./Dez. 2015
}

\title{
ABREVIATURAS NO PERÍODO 1800-1950: NOVA FONTE DE PESQUISA DIACRÔNICA
}

\author{
ELAINE CHAVES \\ Universidade Federal de Minas Gerais \\ JÂNIA MARTINS RAMOS \\ Universidade Federal de Minas Gerais
}

\begin{abstract}
RESUMO: Este artigo tem como objetivo mostrar a contribuição das abreviaturas ao estudo da mudança linguística, identificando-as como pistas gráficas capazes de documentar etapas desse processo. O objeto de análise são as abreviaturas que manifestam o processo iniciado pelo uso de uma expressão nominal Vossa Mercê, que teve como resultado o pronome Você. O período focalizado vai de 1800 a 1950. O objeto de análise são cartas pessoais manuscritas. A abordagem teórico-metodológica utilizada é a Teoria da Variação e Mudança. Foram registradas 32 formas diferentes de abreviar estes itens, aqui tratadas como variantes. Sua sistematicidade foi verificada através de análise quantitativa. Como resultado, foi possível identificar estágios no processo de pronominalização, a partir das abreviaturas.
\end{abstract}

Palavras-chave: abreviaturas; formas de tratamento; século 19.

ABSTRACT: The object of study in this paper is the address forms Vossa Mercê and Você, obtained from manuscript letters written by Brazilians from 1800 to 1950 . Our aim is to show that the investigation of the different ways of writing these address forms could help to account for the the propagation of the change Vossa Mercê $>$ voce across the social system. The Variation Theory is the theoretical-methodological approach used in this research. Our results confirm the relevance of the different abbreviations as clues to study linguistic changes.

Keywords: abbreviations; adress forms; 19 th century.

\section{INTRODUÇÃ̃ ${ }^{1}$}

Identificar e desenvolver abreviaturas constitui uma prática corrente na tarefa de elaborar edições semidiplomáticas. Em várias normas de edição paleográfica e de edição interpretativa, lê-se: "desenvolver as abreviaturas de acordo com as formas por extenso da palavra em questão presentes no modelo" (CAMBRAIA, 2005, p. 119) ${ }^{2}$. Dois exemplos seguem-se abaixo.

${ }^{1}$ Agradecemos a Sueli Coelho (UFMG) pela leitura cuidadosa e seus valiosos comentários Eventuais erros ou inadequações são de nossa inteira responsabilidade.

${ }^{2}$ Ver também Cambraia (2001, 2003), Cambraia et al. (2006), Spina (1994). 


\begin{tabular}{|c|c|}
\hline Transcrição diplomática & Transcrição semidiplomática \\
\hline $\begin{array}{l}\text { (1)Remetto lhe uma ambulancia com os me } \\
\text { dicamentos do costume para o tratamen } \\
\text { to dos cholericos da Ilha do Governador; } \\
\text { e sendo precisos mais alguns objectos para } \\
\text { essefim, com a sua requisição serão em } \\
\text { viados. } \\
\text { Deos guarde a VM } \\
\text { José Luiz Vieira [Camara] [inint.] do [Cunha] } \\
\text { (grifo meu) }\end{array}$ & $\begin{array}{l}\text { (1')Remetto lhe uma ambulancia com } \\
\text { os me | dicamentos do costume para } \\
\text { o tratamen | to dos cholericos da Ilha } \\
\text { do Governador; | e sendo precisos } \\
\text { mais alguns objectos para | essefim, } \\
\text { com a sua requisição serão en | viados. } \\
\text { Deos guarde a V ossa M erce } \\
\text { José Luiz Vieira [Camara] [inint.] do } \\
\text { [Cunha] (grifo meu) }\end{array}$ \\
\hline $\begin{array}{l}\text { (2)E outra Couza He muito bastante para a } \\
\text { SUS } \\
\text { Tentação do Suplicado a vista do que = Pedem } \\
\text { A vms Se dignem deliberar a favor dos } \\
\text { Suplicantes tudo aquillo que acharem jus (gri- } \\
\text { fo meu) }\end{array}$ & 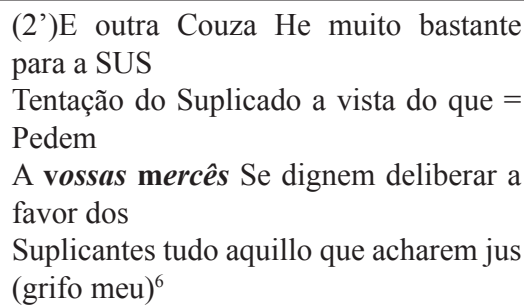 \\
\hline
\end{tabular}

Em (1) e em (2), há duas abreviaturas, VM e vms. Em (1'), a letra inicial está em maiúsculas; já em (2'), está em minúscula. Pode-se perguntar qual a razão dessa diferença. Na edição semidiplomática, o desdobramento da abreviatura resulta em uma expressão nominal composta por dois itens lexicais, sem qualquer perda fonética, conforme se lê em itálico nos dois enunciados, na segunda coluna (o grifo é nosso).

A expressão nominal Vossa Mercê está associada a um processo diacrônico cujo resultado foi o surgimento do pronome 'Você'. Segundo Marilina Luz (1954)', no século XIV, a expressão Vossa Mercê passou a ser usada como forma nominal de tratamento. Vários pesquisadores documentaram diferentes etapas desse processo, sendo quase consensual a aceitação de que o percurso seria tal como representado no esquema (3), em que os locais pontilhados seriam preenchidos por outras formas.

(3) Vossa Mercê $>$ Vossemecê> vosmecê $>$ vancê $>\ldots$. você ${ }^{8}$

Uma das interpretações do esquema (3) é que uma expressão nominal se tornou pronome e o período de tempo em que há maior número de manifestações das

${ }^{3}$ Ofício de 21/01/1856, da Secretaria de Polícia, manuscrito.

${ }^{4}$ Ofício de 21/01/1856 da Secretaria de Polícia, manuscrito.

${ }^{5}$ Doc. 13[435], manuscrito.

${ }^{6}$ Doc. 13[435], manuscrito.

${ }^{7}$ Ver também Nascentes (1956).

${ }^{8}$ O número de formas é bem mais extenso. Basto (1931) aponta os seguintes: Vossemecê, vosmecê, vosmincê, vassuncê, vancê, mecê, ocê, cê. Sobre uma análise detalhada das várias formas, ver Coelho (2008). 
Cadernos de ESTUDOS LINGÜÍSTICOS (57.2) - Jul./Dez. 2015

diferentes realizações é de 1800-1950 (CINTRA, 1986; FARACO, 1996; RAMOS, 2011; LOPES, 2011; dentre vários outros). Uma nova questão se apresenta: que marcas na escrita testemunham etapas do processo de gramaticalização de mudança? Quando identificamos um processo iniciado há vários séculos, temos necessariamente de nos valer de dados da escrita. Geralmente, os pesquisadores levam em conta a grafia das palavras, sua posição na sentença e no texto e, a partir dessas pistas, depreendem processos sintáticos, fonológicos, semânticos, pragmáticos etc. Em outras palavras, quando não dispomos de material sonoro, temos de nos valer de pistas gráficas. Por que não considerar as abreviaturas uma parte desse conjunto?

A utilização de uma única forma por extenso para diferentes abreviaturas é geralmente o expediente adotado em vários estudos, sendo as abreviaturas quase um empecilho. Diferentemente, tomaremos as abreviaturas como uma fonte para a documentação das diferentes etapas do processo de pronominalização. Argumentaremos a favor da inclusão das abreviaturas como um importante instrumento para traçar o percurso da mudança linguística, na medida em que podem ser tomadas como pistas gráficas que auxiliam o pesquisador a reconstituir as diversas etapas do processo.

\section{ANALISANDO ABREVIATURAS}

O uso das abreviaturas não é feito de forma livre, e sim, limitado; depende do contexto, das regras e do local em que são empregadas. A investigação das relações entre o uso de abreviaturas e o contexto situacional, conforme Lopez (s/d), traz informações de profunda importância para a história da língua.

Argumentando na mesma direção, González (2002) acrescenta que diferentes formas de abreviar palavras possuem uma "certa lógica", isto é, o emprego de recursos baquigráficos não é aleatório, mas apresenta uma sistematicidade, o que nos autoriza a tomá-las como objeto de análise na reconstituição de percursos de mudança. Em vista disso, a flutuação observada nas formas não é algo nocivo à compreensão das abreviaturas. Ao contrário: as formas diferenciadas existem por várias razões decorrentes de sua evolução histórica, cujos resultados se manifestam na forma e no uso que temos hoje. As abreviaturas constituiriam, assim, um capítulo da evolução da escrita9 .

Nossa hipótese é, pois, que abreviaturas de itens e de construções sofrem mudança linguística, evoluindo de modo não dissociado dos respectivos itens e construções a elas associados. Desse modo, prevê-se um espelhamento entre ambos, pois seriam afetados por processos mais abstratos, que vão além da

${ }^{9}$ González (2002) descreve que New York tem como variante mais antiga N. Y., com ponto e espaço. Passou a ser grafada N.Y., com ponto e sem espaço. E tem como forma mais moderna NY. As razões desse percurso, segundo González, seriam explicadas pela necessidade de existir uma grafia que não fosse confusa e que estabelecesse um paralelo com a compreensão semântica. 
simples grafia. Para testar essa hipótese, optamos por reanalisar um tema bastante pesquisado na literatura recente: a evolução da expressão nominal Vossa Mercê.

E se, de fato, as abreviaturas evoluem e manifestam processos abstratos gramaticais e sociais -, a simplificação das formas pautada na exoneração dos desenhos das letras, nas letras sobrescritas e na capitalização das letras iniciais estará sofrendo variação e mudança e não simples flutuação. É essa a proposta que pretendemos desenvolver neste artigo.

\section{A INVESTIGAÇÃO DIACRÔNICA}

Assumindo que as escolhas gráficas para abreviar a construção Vossa Mercê não são aleatórias, mas resultantes de condicionamentos, empreendemos uma pesquisa diacrônica com o propósito de testar duas hipóteses enunciadas na seção anterior: (i) a evolução de construções, no eixo diacrônico, afeta a forma pela qual essa construção é abreviada; (ii) as diversas formas de abreviar uma construção configuram uma variável sociolinguística.

Numa pesquisa diacrônica, formamos duas amostras, sendo uma composta de 150 cartas pessoais ${ }^{10}$ manuscritas do período de 1800 a 1950 escritas por brasileiros, e outra composta por peças e romances brasileiros do século $19^{11}$. A amostra principal é a de cartas, por conter somente material manuscrito. A amostra de peças e romances será usada apenas como contraponto, por ser material editado; nela vamos coletar apenas as formas por extenso ${ }^{12}$.

Foram constituídos dois corpora, a partir da amostra principal. O primeiro corpus reuniu as ocorrências das abreviaturas de formas de tratamento, obtendose um total de 194 dados. O segundo corpus reuniu as ocorrências de formas de tratamento por extenso, obtendo-se um total de 191 dados. Um terceiro corpus foi composto por formas por extenso encontradas em peças e romances, mas esse não foi quantificado ${ }^{13}$.

Ocorrências do primeiro corpus aparecem exemplificadas a seguir.

\footnotetext{
${ }^{10}$ Para a interpretação histórica e conceitual das cartas pessoais, ver Tin (2005) e Silva (1997).

${ }^{11}$ Teoria do medalhão (1881), de Machado de Assis; Pelo Sertão e Os Jagunços (1898), de Afonso Arinos; A capital federal (1897) e Amor por Anexins (1872), de Artur Azevedo.

${ }_{12}$ No Vocabulário Ortográfico da Academia Brasileira de Letras, há a indicação de que a abreviatura $\mathrm{Vm}^{c e}$ corresponde ao pronome Vossa Mercê e a abreviatura $\mathrm{vm}^{c e}$ corresponde às formas Vossemece ou Vosmece. Por essa razão, era necessário que houvesse um corpus no qual as formas de tratamento pesquisadas fossem intencionalmente escritas por extenso. O testemunho dos textos literários teria a função de mostrar se, realmente, as formas Vossemece e Vosmece ocorriam no mesmo período de tempo em que a abreviatura $v^{c e}$, para que assim pudéssemos abonar a assertiva da Academia Brasileira de Letras. A abreviatura é mais frequente nas cartas pessoais, na segunda metade do século XIX, mesmo período que textos literários (nota 11) mostram uso sistemático do item Vosmecê.

${ }^{13}$ A não quantificação do corpus de textos literário se deveu ao fato de se tratar de textos editados, sem edição crítica, o que não permitiu computar o quanto as informações dali retirados eram fruto da vontade do autor ou de terceiros. Essa impossibilidade de controle da amostra poderia resultar em um resultado enviesado.
} 
Cadernos de ESTUDOS LINGüISTIICOS (57.2) - Jul./Dez. 2015

(4) eu não quero usar dele Vm bem me entenda (carta XLVII, 1874)

(5) enconçiençia que $\mathrm{Vm}^{\text {ce }}$ hade ter susego (carta XLVIII, 1874)

(6) passo a rogar a vm. ${ }^{\mathrm{ce}}$ para que sabendo (carta VI, 1828)

(7) Que vm ${ }^{\text {ce }}$. hade areceber oleite (carta XL, 1848)

Nesses enunciados, podem ser observadas abreviaturas contendo ou não ponto abreviativo, tal como em (6) e em (7); contendo ou não letras sobrescritas, como em (5), em (6) e em (7); iniciadas ou não por letra maiúscula, como em (4), em (5), em (6) e em (7), respectivamente. São, portanto, vários os parâmetros a partir dos quais as abreviaturas podem ser descritas. Veja-se o detalhamento no Quadro 1, a seguir:

Quadro 1: Descrição das abreviaturas, conforme tipo de diacrítico e capitalização da letra inicial, por século.

\begin{tabular}{|c|c|c|c|}
\hline & $1^{\mathrm{a}}$ metade do XIX & $2^{\mathrm{a}}$ metade do XIX & $1^{\mathrm{a}}$ metade do $\mathrm{XX}$ \\
\hline $\mathrm{VM}^{\mathrm{ce}}$ & & & \\
\hline $\mathrm{Vmc}^{\mathrm{e}}$ & & & \\
\hline $\mathrm{Vm}^{\mathrm{e}}$ & & & \\
\hline Vm" & & & \\
\hline $\mathrm{Vm}^{\mathrm{ce} "}$ & & & \\
\hline $\mathrm{Vm}^{\mathrm{ce}}$ & & & \\
\hline $\mathrm{Vm}^{\mathrm{e}}$ & & & \\
\hline $\mathrm{vm}^{\mathrm{CE}}$ & & & \\
\hline $\mathrm{vm}^{\text {ces }}$ & & & \\
\hline $\mathrm{vm} \cdot{ }^{\text {ces }}$ & & & \\
\hline $\mathrm{vm}^{\mathrm{e}}$ & & & \\
\hline $\mathrm{vo}^{\mathrm{CE}}$ & & & \\
\hline $\mathrm{vm}^{\text {ces }}$ & & & \\
\hline $\mathrm{vo}^{\mathrm{ce}}$ & & & \\
\hline VM & & & \\
\hline $\mathrm{Vm}^{\mathrm{ce}}$ & & & \\
\hline $\mathrm{Vm}$ & & & \\
\hline $\mathrm{vm}^{\mathrm{ce}}$ & & & \\
\hline $\mathrm{vm}$ & & & \\
\hline $\mathrm{VM}^{\text {ces }}$ & & & \\
\hline $\mathrm{Vm}^{\text {ces }}$ & & & \\
\hline $\mathrm{Vm}^{\text {ces }}$ & & & \\
\hline
\end{tabular}




\begin{tabular}{|c|l|l|l|}
\hline Vac. $^{\text {e }}$ & & & \\
\hline $\mathrm{Vm}^{\mathrm{ce}}$ & & & \\
\hline $\mathrm{Vm}^{\mathrm{ce}}$ & & & \\
\hline $\mathrm{VC}^{\mathrm{e}}$ & & & \\
\hline $\mathrm{VC}$. & & & \\
\hline $\mathrm{VC}$ & & & \\
\hline $\mathrm{VC}$ & & \\
\hline $\mathrm{V} .^{\mathrm{ce}}$ & & & \\
\hline $\mathrm{V} \cdot{ }^{\mathrm{ce}}$ & & & \\
\hline $\mathrm{Vc}$ & & & \\
\hline
\end{tabular}

Observemos a diversidade de abreviaturas, distribuídas por século. Foram encontradas 32 formas diferentes no corpus $^{14}$. A leitura vertical do quadro permite observar uma tendência de simplificação, que se manifesta na perda de letras sobrescritas, de aspas duplas, de pontos abreviativos. Além das formas vm e de v. cê $^{\text {en }}$ com minúsculas aparece $\mathrm{Vac}^{e}$, que é, possivelmente, a abreviatura de vancê. Notese que Vancê é uma das várias realizações intermediárias no processo apresentado em (3) e repetido, a seguir, com nova numeração.

(8) Vossa Mercê $>$ Vossemecê $>$ vosmecê $>$ vancê $>$ vosce $>$ você

Se tivermos em conta apenas as abreviaturas do Quadro I em que há ce sobrescrito, é possível depreender cinco estágios.

(9) $\mathrm{VM}^{\mathrm{ce}}>\mathrm{Vm}^{\mathrm{ce}}>\mathrm{Vm}^{\mathrm{ce}}>\mathrm{Va}^{\mathrm{ce}}>\mathrm{Vo}^{\mathrm{ce}}$

(CHAVES, 2006, p.100)

Certamente não é coincidência o pareamento entre as formas por extenso em (8) e as abreviaturas em (9).

É exatamente essa a correlação estabelecida no Vocabulário Ortográfico da Lingua Portuguesa $(1981,1997)^{15}$ da Academia Brasileira de Letras, onde se lê que a forma abreviada Vm ${ }^{c e}$ corresponde a Vossa Mercê e a forma abreviada vm ${ }^{c e}$ corresponde a Vossemecê ou Vosmecê. No Brasil, as formas em (8) são registradas em romances e em peças teatrais na segunda metade do século 19 , conforme dados extraídos do terceiro corpus de nossa amostra.

${ }^{14}$ FLEXOR, M.H.O. (1991), em seu dicionário de abreviaturas, registra 40 formas diferentes para Vossa Mercê.

${ }^{15}$ Essa convenção foi adotada em quase todos os Vocabulários confeccionados a partir do Vocabulário da ABL (A. ALBUQUERQUE, 1953; AMORA, 1958; etc.). 
(10) Há seis anos que estou a serviço de vossemecê. (Filomena Borges, Aluísio Azevedo, 1884)

(11) Salvo se vossemecês metem também na conta o que quebrou Brás! (Casa de Pensão, Aluísio Azevedo, 1884)

(12) Olhe do que vosmecê escapou, disse o almocreve. (Memórias Póstumas de Brás Cubas, 1881)

(13) Vancê tá assistino aqui? (Artur Azevedo, 1907)

Sendo as formas vossemecê e vosmecê frequentes no período de tempo analisado ${ }^{16}$, parece razoável concluir que seria mais adequado desenvolver as abreviaturas $v m^{c e}$ e $v m$ como vossemecê e vosmecê, respectivamente. Por isso, discordamos de que o desdobramento de $v m$ seja Vossa Mercê, como costumeiramente tem sido feito em edições de textos diacrônicos de língua portuguesa, conforme vimos nos exemplos (1') e (2'), na introdução do presente artigo.

Retomemos mais uma vez o Quadro 1. Supondo-se que $V C$ e $v^{c \hat{e}}$. sejam abreviaturas do item você e que $V M$ e $v m$ sejam representações de outras realizações do mesmo processo de mudança, podemos capturar um padrão: o uso de maiúsculas e de minúsculas.

Tal como Marquilhas (1988), vamos adotar a capitalização inicial - presença ou ausência de maiúscula - como uma categoria de análise. A capitalização da inicial é um elemento abstrato, que ultrapassa "o nível do grafema enquanto unidade discreta e se aplica a sequências inteiras de grafemas e só pode ser entendido com uma instrução para se transformarem grafemas não marcados em grafemas marcados" (Marquilhas, 1988: 124). Esse tipo de "realce" traz consigo informações semânticas que têm a ver com o conceito de grandeza: "geográfica (topônimos em geral), de consagração social (vocabulário aristocrático, nomes profissionais), de consagração espiritual (vocabulário religioso), de número (nomes referentes a comunidades humanas), etc." (idem, 126). O uso de iniciais maiúsculas ou minúsculas em um mesmo item "revela uma hesitação quanto aos contornos precisos de grandeza semântica cristalizável em termos gráficos." (idem, 126).

Diferentemente de Marquilhas (1988), vamos identificar a capitalização como variável sociolinguística. As realizações de maiúscula inicial ou minúscula inicial serão as variantes. Nossa hipótese é que a distinção entre maiúsculas e minúsculas manifestaria nas abreviaturas o seguinte processo:

(14) forma de reverência > perda desse estatuto

Encontramos em gramáticas de época razões que reforçam nosso tratamento do tema, conforme será demonstrado na próxima seção.

\footnotetext{
${ }^{16}$ Ver análise das Formas de tratamento nas peças de Arthur Azevedo (Ramos, em andamento).
} 


\section{INVESTIGANDO GRAMÁTICAS}

A consulta a gramáticas normativas do século $19^{17}$ revelou que havia recomendações sobre o uso de abreviaturas.

(15) Usa-se de algumas abreviaturas para as quaes não há regras seguras, por isso deve-se nestes casos proceder de modo que as letras escriptas dêm a conhecer facilmente as palavras que queremos representar, como: SSmo Santissimo, Ex.mo Excellentissimo, Illmo Illustrissimo, R.mo Reverendissimo, Sr. Senhor, $\mathrm{Sr}^{\mathrm{a}}$ Senhora; Ant. ${ }^{\circ}$ Antonio; M.to Muito (A. ALBUQUERQUE, 1854, p. 113)

Duas informações chamam a atenção aqui. A primeira é que as regras quanto ao uso de maiúsculas não são seguras, o que implica reconhecer que há heterogeneidade de formas. A segunda é a recomendação quanto à preocupação com transparência entre a abreviatura e a palavra que o falante quis representar, de modo que ele a dê a conhecer facilmente.

No que diz respeito especificamente às formas em apreço aqui, os gramáticos explicitamente recomendam o uso de maiúsculas ${ }^{18}$. Veja-se Pereira, em sua Grammatica Expositiva, cuja primeira edição data de 1886 (a segunda edição é de 1907).

(16) (...) Escrevem-se em letra maiúscula inicial: (...) 4. Os títulos de honra e dignidade: V. $\mathrm{S}^{\mathrm{a}}$. - Dr. - Ver. - Snr. - D. - $\mathrm{P}^{\mathrm{e}}$. (...)

Nota - Vae-se generalisando no jornalismo o uso de minúsculas neste caso. (PEREIRA, 1907, p. 324, grifo nosso)

A citação (16) contém a transcrição de uma nota. Nela Pereira atribui à imprensa o papel de agente inovador na disseminação de uma prática que contradiz a recomendação. Tal comentário parece ter um tom de repreensão.

Esse comentário é importante porque confirma não haver homogeneidade. Temos aqui um relato de uso por alguém contemporâneo do uso. É possível inferir, então, a presença de um processo de variação sociolinguística manifestado na escrita. O comentário de que a imprensa seria o agente responsável pela inovação permite identificar qual a forma inovadora e, também, introduzir um referente ao tempo real na análise. A observação sobre o modo como esta norma (não) está sendo acatada pela imprensa aparece em nota, o que leva a supor que havia uma atitude, até certo ponto, negativa em relação à inovação.

$\mathrm{O}$ fato de o uso de maiúsculas ser passível de registro em gramáticas normativas permite formular a hipótese de que esse uso será favorecido em textos

${ }^{17}$ Ribeiro, J. 1860; Borges, 1877; Oliveira, 1880; Pardal, 1879; etc.

18 Sobre o uso de abreviaturas, além das gramáticas do século 19, ver Tauste (1999) e o artigo Abreviaturas, disponível em: <http:// www. belcart.com/belcart_es/como_esc/c_abreviat.html $>$, acesso em 20/06/2007. 
Cadernos de ESTUDOS LINGüISTICOS (57.2) - Jul./Dez. 2015

cujos assuntos pertençam à esfera pública, sendo o uso de minúsculas favorecido em textos cujos assuntos pertençam à esfera privada. Outra hipótese é que iniciais maiúsculas indicariam tratamento de cortesia e reverência; já as iniciais minúsculas indicariam ausência de reverência.

Estas hipóteses levaram à formulação de fatores condicionadores externos, aos quais as ocorrências do corpus foram submetidas para efeito de análise quantitativa. Os resultados obtidos aparecem nas Tabelas 1 e 2, e no Gráfico 1, a seguir. Todos os fatores citados a seguir foram selecionados pelo Programa Varbrul, versão Goldvarb 2001, o que significa terem sido considerados quantitativamente significativos.

O primeiro fator extralinguístico testado foi o fator tempo. Foram definidos três períodos: primeira e segunda metades do século 19 e primeira metade do século 20. O resultado aparece no formato de um gráfico que registra o perfil, em peso relativo, das abreviaturas iniciadas com letra minúscula.

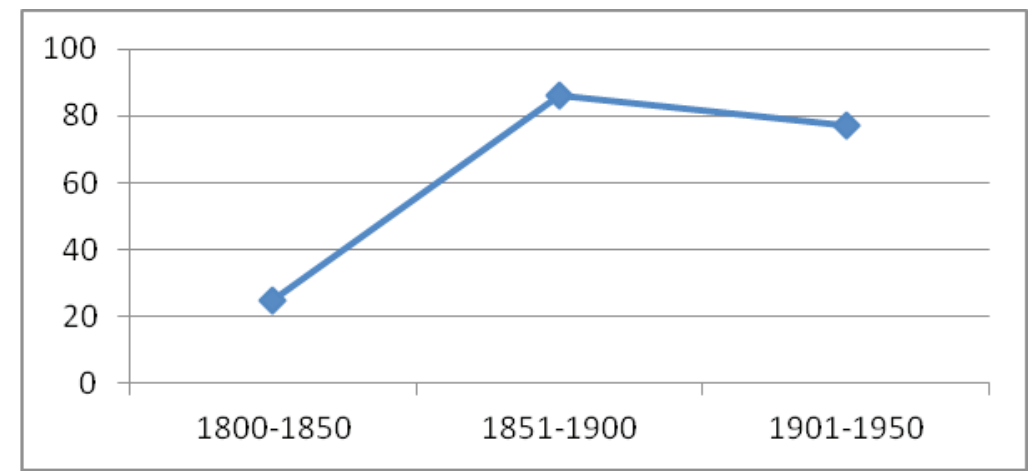

Gráfico 1: Distribuição da variante de inicial minúscula, em três períodos de tempo, em correspondências.

O gráfico mostra um perfil ascendente no primeiro intervalo de tempo. Nele se observa, na primeira metade do século 19, que a frequência de abreviaturas com letra inicial minúscula é relativamente baixa (.25), mas rapidamente avança e chega a .75 na primeira metade do século 20. Tem-se, pois, uma mudança no padrão de registro de formas de tratamento, e não só isso, conforme veremos mais adiante.

O outro fator testado foi o tipo de assunto: se assunto de esfera pública ou assunto de esfera privada. O critério adotado consistiu em classificar como pertencentes à esfera privada as cartas que versavam sobre assuntos familiares, favores e trocas feitas entre amigos. Já as cartas que versavam sobre assuntos políticos, consultas ou pedidos notariais foram classificadas como pertencentes à esfera pública, conforme ilustram, respectivamente, os excertos (17) e (18):

(17) Faço esta so para saber da saudade/meu pai Minha Mai Vó e mana e de todos. (...)Vm queira me lançar a/sua benção, e tao bem minha Mai 
e Vó e eu asrecebo como/Lembranças/ aminha mana [espaço] Filho amante obrigado/a Maria do Carmo_/sua e todos (carta V, 1825)

(18) mefalta pagar aos Professores e o Botica, epor hiço já não vai aConta Corrente para vossamerce ver (carta III, 1811)

\begin{tabular}{|c|c|c|c|}
\hline Assunto & No. & $\%$ & PR \\
\hline Público & 28 & 26 & 0.32 \\
\hline Privado & 38 & 39 & 0.77 \\
\hline
\end{tabular}

Tabela 1: Distribuição da variante com minúscula conforme o assunto da correspondência.

O favorecimento de abreviaturas com iniciais minúsculas em cartas cujo assunto é de esfera privada confirma que essa variante manifesta ausência de reverência no conteúdo da forma de tratamento, confirmando o padrão aventado no esquema (14), como hipótese. O avanço das abreviaturas em minúsculas, registrado no Gráfico 1, parece, portanto, testemunhar a etapa de perda do estatuto de reverência das formas de tratamento. Essa perda constitui, por sua vez, uma etapa importante no processo de pronominalização cujo resultado é o uso da forma você sem qualquer conotação de reverência, no momento atual no Brasil ${ }^{19}$.

Além da sistematicidade da capitalização inicial nas formas de tratamento, nossa análise permitiu identificar dois outros tipos de ocorrências: formas por extenso e formas abreviadas, conforme já mencionamos. As formas por extenso precederam, cronologicamente, as formas abreviadas, o que leva à seguinte sequência de uso:

(19) Forma de tratamento por extenso

Abreviatura iniciada por maiúsculas

\section{Abreviatura iniciada por minúsculas ${ }^{20}$}

Uma evidência a favor da sistematicidade representada em (19) pode ser obtida ao observarmos as ocorrências de você. Mesmo quando vm já era mais frequente, aparece a realização $V C$. Se nossa análise estiver correta, os contextos de $V C$ serão mais formais que os contextos de $v c$ no nosso corpus. Isso foi

\footnotetext{
${ }^{19}$ A aceitação do tratamento por você aos pais, efetivado por filhos nascidos a partir dos anos 70 , é uma evidência disso (Ramos, 2011).

20 “Os estudos de Soto (2001, 2007), Lopes e Duarte (2003), Lopes e Machado (2005), Rumeu (2008) e Lopes $(2009,2011)$ mostraram que o tratamento você no século XIX apresentava um comportamento híbrido e instável, pois aparecia tanto como uma estratégia de prestígio usada pela elite brasileira da época, quanto como um tratamento generalizado em cartas de cunho doméstico ao lado de tu" (Lopes, C. 2012, v.1:5).
} 
Cadernos de ESTUDOS LINGüISTIICOS (57.2) - Jul./Dez. 2015

exatamente o que ocorreu. Todos os dados encontrados eram de cartas com assunto privado, escritas por homem. Houve uma única ocorrência de inicial minúscula entre amigos que mantinham relação de solidariedade semântica, expressa em um contexto menos formal. As outras dezesseis ocorrências aconteceram entre parentes que mantinham relação de poder semântico (díades pai/ filho e padrinho/ afilhado), caracterizando contexto mais formal que o anterior.

Cabe, neste momento, ressaltar que, no estudo das formas de tratamento, as abreviaturas, em vez de representarem um mascaramento dos estágios da transformação pronominal, evidenciam diferentes estágios do processo, na medida em que são muito frequentes e sistemáticas, pelo menos em cartas, peças e romances do período analisado.

\section{CONCLUSÕES}

Vários estudos tratam a forma Você como resultado de uma mudança linguística a partir da construção Vossa Mercê. A análise das abreviaturas aqui apresentada mostrou que é possível recuperar, através da escrita, detalhamentos desse processo, usando o instrumental metodológico da teoria da variação.

O dicionário de abreviaturas de Flexor (1985), conforme mencionamos na nota 11, apresenta um grande número de abreviaturas para Vossa Mercê, mais precisamente 40. Estas são, por vezes, acompanhadas de datação. Embora de grande ajuda para o pesquisador, o dicionário não estabelece correlações entre as abreviaturas nem identifica padrões. Essa não é uma crítica ao dicionário, porque sua função não é a de apresentar tais padrões. O que se pretende aqui é mostrar que, além do que aparece no dicionário, é possível saber mais sobre as abreviaturas.

A investigação do percurso histórico das abreviaturas em análise permitiu verificar uma simplificação das suas formas pautada na exoneração dos desenhos das letras, bem como das letras sobrescritas e do ponto abreviativo, conforme o Quadro I. Se estivermos corretas, estaremos ampliando o objeto da teoria da variação, incorporando a seu escopo fenômenos peculiares à escrita. É essa a linha de investigação a favor da qual argumentamos aqui.

O termo variante gráfica, pelo qual nos referimos à variação entre iniciais maiúsculas e minúsculas das formas de tratamento, foi utilizado por Rita Marquilhas (1988) ao tomar como objeto de estudo anotações em textos do século XVIII encaminhados à imprensa. É um estudo das variantes gráficas com o objetivo de construir a normalização gráfica no século XVIII. A autora se atém a variantes gráficas decorrentes de processos fonológicos. As variantes gráficas decorrem de processos fonológicos, mas não apenas deles, conforme vimos.

Marquilhas (1988) divide as variantes gráficas em três categorias: a) capitalização da inicial - presença ou ausência de inicial maiúscula; b) etimologização gráfica - presença ou ausência de sistemas gráficos clássicos feitos a partir de empréstimos, e c) acentuação e hifenação - presença ou ausência de sinais não alfabéticos. 
A categoria em que nos detivemos foi a capitalização da inicial. Esperamos ter confirmado que o uso das abreviaturas sistemático e que esse uso pode ser verificado através da relação entre a escolha da forma de abreviar, levando em conta o tempo e o tipo de assunto e, indiretamente, a relação social entre emissor e recebedor da carta. Sendo assim, a relação semântica entre o uso gráfico e o conceito de grandeza nos leva à relação posição social, hierarquia e grafia. Para verificar a autenticidade essa hipótese, foi necessário testar se havia sistematicidade na flutuação das abreviaturas, o que foi comprovado por nossos dados. Assim, foi possível descrever a flutuação dessas formas como variação e chegar ao estudo diacrônico de um conjunto de abreviaturas, mais exatamente, ao conjunto de abreviaturas de formas de tratamento como objeto de variação linguística.

\section{REFERÊNCIAS BIBLIOGRÁFICAS}

Abreviaturas. Disponível em: <http:// www. belcart.com/belcart_es/como_esc/c_abreviat.html $>$ Acesso em: 18 jun. 2006.

Academia Brasileira de Letras. "Pequeno Vocabulário Ortográfico da Língua Portuguesa". 2a ed. Rio de Janeiro: Corbã Editoras Artes Gráficas, 1997. 1097 p.

Academia Brasileira de Letras. "Vocabulário Ortográfico da Língua Portuguesa". 1ª ed. Rio de Janeiro: Bloch, 1981. 795 p.

AGUILERA, W.A. \& VASCONCELOS, C.A. (orgs.) Scripturae nas Vilas de São Luiz de Goaratatuba e Antonia: manuscritos setecentistas e oitocentistas. Londrina: Universidade Estadual de Londrina, 2007. (ISBN 978-85-98196-61-9) Disponível em: $<$ https://docs.google.com/viewer?a=v\&pid=sites\&srcid=ZGVmYXVsdGRvbWFpbnxjb3Jwb3JhcGhwYnxneDoxZjAwMWI0NmM wNGV1MGM5>. Acesso em: 5 abr. 2013.

ALBUQUERQUE, A. Tenório. Vocabulário Ortográfico da Língua Portuguesa. Rio de Janeiro: Gráfica Editora Aurora, 1953. 1165 p.

ALBUQUERQUE, Salvador Henrique de. Compendio de Grammatica Portuguesa. 12a ed. Rio de Janeiro: A. A. Lopes do Couto, 1854. 156 p.

AMORA, Antonio Soares. Vocabulário Ortográfico da Língua Portuguesa. São Paulo: LEP, 1958. 885 p.

BASTO, Cláudio. Formas de tratamento, em português. Revista Lusitana. Porto, 1931. pp. 183-202.

BORGES, Dr. Abílio César. Resumo da gramática Portuguesa para uso das escolas. $7^{\mathrm{a}}$ ed. 1877. pp. 129-130.

CAMBRAIA, C. N. Crítica textual \& linguística histórica: a questão dos diacríticos. Caligrama. v. 8. Belo Horizonte: UFMG. pp. 21-40, 2003.

CAMBRAIA, C. N. Introdução à crítica textual. São Paulo: Martins Fontes, 2005. 216 p.

CAMBRAIA, C. N.; OLIVEIRA, Gilvan Muller; MEGALE, H.; Modolo, Marcelo; FERREIRA, Permínio de Souza; TOLEDO NETO, S. A.; LOBO, Tânia; KLAMT, Valdemir. Normas para 
transcrição de documentos manuscritos para a história do Português do Brasil" In: MEGALE, Heitor, NETO \& Sílvio de Almeida Toledo. (Org.). Por minha letra e sinal. 1 ed. v. 1. São Paulo/ Cotia-SP: Fapesp/ Ateliê, 2006. pp. 145-148.

CAMBRAIA, César Nardelli (2001). Subsídios para a fixação de normas de transcrição de textos para estudos linguísticos - I. In: Mattos e Silva, R. V. (org.). Para História do Português Brasileiro. v. 2. Tomo 2. São Paulo: Humanitas, 2001. pp. 531-534.

CHAVES, Elaine. A Implementação do pronome Você: a contribuição das pistas gráficas. 2006. Dissertação (Mestrado em Estudos Linguísticos) - Faculdade de Letras, UFMG, 2006. 273 p.

CINTRA, L. Sobre ‘formas de tratamento’ na língua portuguesa. Lisboa: Horizonte, 1986.

DOCUMENTO. 13[435], fólio 1 verso; trata do pagamento de dízimo pelos fiéis, data 26/04/1803, autor Manoel Baldoino Lopez. Transcrição feita por Aguilera, W.A. \& Vasconcelos, C.A. (orgs.) Scripturae nas Vilas de São Luiz de Goaratatuba e Antonia: manuscritos setecentistas e oitocentistas. Londrina: Universidade Estadual de Londrina, 2007. (ISBN 978-85-98196-61-9) Disponível em: $<$ https://docs.google.com/viewer?a=v\&pid=sites\&srcid=ZGVmYXVsdGRvbWFpbn xjb3Jwb3JhcGhwYnxneDoxZjAwMWI0NmMwNGVIMGM5>. Acesso em: 5 abr. 2013.

DOCUMENTO. 13[435], fólio 1 verso; trata do pagamento de dízimo pelos fiéis, data 26/04/1803, autor Manoel Baldoino Lopez. Transcrição feita por Aguilera, W.A. \& Vasconcelos, C.A. (orgs.) Scripturae nas Vilas de São Luiz de Goaratatuba e Antonia: manuscritos setecentistas e oitocentistas. Londrina: Universidade Estadual de Londrina, 2007. (ISBN 978-85-98196-61-9) Disponível em: $<$ https://docs.google.com/viewer?a=v\&pid=sites\&srcid=ZGVmYXVsdGRvbWFpbn xjb3Jwb3JhcGhwYnxneDoxZjAwMWI0NmMwNGVIMGM5>. Acesso em: 5 abr. 2013.

FARACO, Carlos Alberto. "O Tratamento Você em Português: uma abordagem histórica". Fragmenta 13, Curitiba, pp. 51-82, 1996.

FLEXOR, M. H. O. Abreviaturas: Manuscritos dos séculos XVI ao XIX. São Paulo: UNESP. Secretaria de Estado da Cultura. Arquivo do Estado de São Paulo, 1991. 389p.

GONZÁLEZ, Félix Rodríguez. Variación tipográfica en el uso de las "abreviaturas". 2002. Disponível em: $<$ http://www.ucm.es/info/especulo/cajetin/abreviat.html $>$ Acesso em: 18 jun. 2006.

LOPES, Célia Regina dos Santos; SOUZA, Janaina Pedreira Fernandes. Os caminhos trilhados por você... em cartas cariocas (século XIX-XX). In: LOBO, Tânia et alii. (Org.). ROSAE: Linguística histórica, história das línguas e outras histórias.1 ed.Salvador: EUFBA, 2012, v.1.

LOPES, C. R. S. A cronologia do voceamento no português brasileiro: expansão de você-sujeito e retenção do clítico-te. Linguistica. v. 25. Madrid, 2011. p. 30-65.

LOPES, C. R. S.; MACHADO, A. C. M. Tradição e inovação: indícios do sincretismo entre a segunda e a terceira pessoas nas cartas dos avós. In: LOPES, C. R. dos. S. (Org.) A Norma Brasileira em Construção. Fatos linguísticos em cartas pessoais do século 19. Rio de Janeiro: UFRJ/ Pósgraduação em Letras Vernáculas/FAPERJ, 2005.

LOPES, Célia e DUARTE, Maria Eugenia Lamoglia. De Vossa Mercê a você: análise da pronominalização de nominais em peças brasileiras e portuguesas setecentistas e oitocentistas. In: BRANDÃO, Silvia Figueiredo e MOTA, Maria Antonia. (org). Análise constrativa de variedades do português: primeiros estudos. $1^{\mathrm{a}}$ ed. Rio de Janeiro: In-Fólio, 2003. pp. 61-76. 
LUZ, Marilina dos Santos. Fórmulas de Tratamento no Português Arcaico. Revista Portuguesa de Filologia. v. II, T. I, II. Coimbra, 1954. p. 256-363.

MARQUILHAS, Rita. O original da imprensa e a normalização gráfica no século XVIII. 1998. Dissertação (Mestrado em Linguística Histórica Portuguesa) - Faculdade de Letras, Universidade de Lisboa, Lisboa, 1988. 193 p.

NASCENTES, Antenor. O tratamento de "você" no Brasil. Revista Letras, Curitiba, v. 5, n. 6, p. 114257. 1956.

OFÍCIO de 21/01/1856 da Secretaria de Polícia ao Dr. José Antonio de Sousa Gomes, encarregado dos doentes da Ilha do Governador, sobre remessa de medicamentos. Secretaria de Policia da Corte 21 de Janeiro de 1856. Data: 12 de fevereiro de 1891;Fonte: Arquivo Nacional do Rio de Janeiro;Autor/Naturalidade e/ou Nacionalidade: José Luiz Vieira [Camara da Cunha]/ naturalidade desconhecida; Referência: AN/Coleção Família Souza Gomes 49CP17. Edição / Revisão: SILVA, Andrezza, / VIANNA,J.,LOPES,C.\& BARBOSA, A.o de Janeiro. Disponível em: $<$ http://www.letras.ufrj.br/phpb-ri/corpora/xix/particulares/cartas_rj_natdesc.htm>. Acesso em: 5 abr. 2013.

OFÍCIO de Ofício de 21/01/1856 da Secretaria de Polícia ao Dr. José Antonio de Sousa Gomes [26], encarregado dos doentes da Ilha do Governador, sobre remessa de medicamentos. Secretaria de Policia da Corte 21 de Janeiro de 1856. Edição / Revisão: SILVA, Andrezza, / VIANNA,J.,LOPES,C.\& BARBOSA, A.o de Janeiro Data: 12 de fevereiro de 1891;Fonte: Arquivo Nacional do Rio de Janeiro;Autor/Naturalidade e/ou Nacionalidade: José Luiz Vieira [Camara da Cunha]/naturalidade desconhecida; Referência: AN/Coleção Família Souza Gomes 49CP17;Observações: Disponível em: $<$ http://www.letras.ufrj.br/phpb-rj/corpora/xix/ particulares/cartas ri natdesc.htm>. Acesso em: 5 abr. 2013.

OLIVEIRA, Bento José de. Nova Grammatica Portuguesa. 13 ed. Coimbra: Livraria de J. Augusto Orgel, 1880. $152 \mathrm{p}$.

PARDAL, Dr. Ortiz. Grammatica analytica e explicativa da Lingua Portuguesa. Rio de Janeiro: Nicoláo-Alves, 1879. 148 p.

PEREIRA, Eduardo Carlos. Grammatica Expositiva (curso superior). 24 ed. (Melhorada e ampliada com uma syntese e critica das Reformas Orthographicas e um Appendice sobre estylistica e Composição litarária em prosa e verso). São Paulo: Companhia Editora Nacional, 1907. p. 251256.

PEREIRA, Eduardo Carlos. Grammatica Expositiva. Curso Superior. São Paulo: Companhia Editora Nacional, 1886. $425 \mathrm{p}$.

RAMOS, J. Formas de tratamento nas peças de Arthur Azevedo. Inédito.

RAMOS, J. M. Tratamento na díade pai e filho: o uso de você e senhor. In: Leticia Rebollo Couto; Célia Regina dos Santos Lopes. (Org.). As Formas de Tratamento em Português e em Espanhol/ Las Formas de Tratamiento en Espanol y en Portugues. 1ed.Niterói: Editora da UFF, 2011, v. 1, p. 289-302.

RAMOS, Jânia Martins. O Uso das Formas Você, Ocê e Cê no Dialeto Mineiro. In: DA HORA, Dermeval (org). Diversidade Linguística no Brasil. João Pessoa: Idéia, 1997. pp. 43-60.

RIBEIRO, João. Gramatica Portuguesa. s/l: s/e, 1860. 356 p. 
RUMEU, M. C. B. . A Variação 'Tu' e 'Você' nas cartas pessoais oitocentistas e novecentistas da Família Pedreira Ferraz - Magalhães: um estudo em tempo real. In: XV Congreso Internacional de La Asociación de Linguística y Filologia de América Latina - ALFAL, 2008, Montevidéu. XV Congreso Internacional de la Asociación de Linguistica y Filología de América Latina, 2008.

SILVA, V.L. P. Cartas Cariocas. A Variação do Sujeito na Escrita Informal. 1998. Tese (Doutorado) Faculdade de Letras, UFRJ, Rio de Janeiro, 1998.

SOTO, Ucy . Cartas através do tempo: o lugar do outro na correspondência brasileira [ISBN 85-2280422-2]. Niterói: EdUFF, 2007.

SOTO, Ucy . Trabalhando com cartas. Boletim do Programa Salto Para o Futuro Série Varal de Textos, Rio de Janeiro, p. 23-30, 2002.

SPINA, Segismundo. "Apontamentos diplomáticos”. In: Introdução à ecdótica; crítica textual. 2. ed. rev. atual. São Paulo: Ars Poética/EDUSP, 1994. 153 p.

TAUSTE, Ana María Vigara. Abreviaturas dobles (CC. OO.). 1999. Disponível em: < http://www.ucm. es/info/especulo/cajetin/cc oo.html> Acesso em: 22 set. 2004.

TIN, Emerson (org.). Arte de escrever cartas: Anônimo de Bolonha, Erasmo de Rotterdam e Justo Lípsio. Campinas: Unicamp, 2005. 165 p. 